Case, J. L., L. T. Wood, J. L. Blaes, K. D. White, C. R. Hain, and C. J. Schultz, 2021: Soil moisture responses associated with significant tropical cyclone flooding events. J. Operational Meteor., 9 (1), 1-17, doi: https://doi.org/10.15191/nwajom.2021.0901.

Journal of Operational Meteorology
Article

\title{
Soil Moisture Responses Associated with Significant Tropical Cyclone Rainfall Events
}

\author{
JONATHAN L. CASE* \\ ENSCO, Inc./Short-term Prediction Research and Transition (SPoRT) Center, Huntsville, Alabama \\ LANCE T. WOOD \\ NOAA/National Weather Service, Houston/Galveston, Texas \\ JONATHAN L. BLAES \\ NOAA/National Weather Service, Raleigh, North Carolina \\ KRISTOPHER D. WHITE \\ NOAA/National Weather Service, Huntsville, Alabama \\ CHRISTOPHER R. HAIN and CHRISTOPHER J. SCHULTZ \\ NASA Marshall Space Flight Center, Huntsville, Alabama
}

(Manuscript received 3 April 2020; review completed 6 December 2020)

\begin{abstract}
Several historic rainfall and flooding events associated with Atlantic Basin tropical cyclones have occurred in recent years within the conterminous United States: Hurricane Joaquin (2015) in early October over South Carolina; Hurricane Harvey (2017) in late August over southeastern Texas; Hurricane Florence (2018) in September over North Carolina; and Tropical Storm Imelda (2019) in September, again over southeastern Texas. A common attribute of these events includes a dramatic transition from dry soils to exceptional flooding in a very short time. We use an observations-driven land surface model to measure the response of modeled soil moisture to these tropical cyclone rainfall events and quantify the soil moisture anomalies relative to a daily, county-based model climatology spanning 1981 to 2013. Modeled soil moisture evolution is highlighted, including a comparison of the total column $(0-2 \mathrm{~m})$ soil moisture percentiles (derived from analysis values) to the 1981-2013 climatological database. The South Carolina event associated with Hurricane Joaquin resulted in a sudden transition from severe drought to significant flooding in the span of a few days, due to locally 700+ mm of rainfall. The prolonged heavy rainfall associated with Hurricane Harvey resulted in record soil moisture values well in excess of the tail of the climatological distribution. The soil moisture west of the Houston, Texas, metropolitan area was anomalously dry prior to Harvey, but quickly transitioned to near saturation in the top 1 $\mathrm{m}$, while east of the Houston area antecedent soil moisture values were more moist prior to the local $1200+\mathbf{m m}$ of rainfall and catastrophic flooding in the Beaumont/Port Arthur area. Hurricane Florence led to widespread 500-700+ $\mathbf{m m}$ of rainfall in North Carolina, and another dramatic transition from anomalously dry conditions to record wetness. Once again, with Tropical Storm Imelda, portions of southeastern Texas experienced extreme rainfall amounts up to $1000+\mathrm{mm}$, resulting in another sharp transition from drought conditions to extreme flooding in $<3$ days. An experimental forecast soil moisture percentile is presented for the Imelda event, showing the potential to increase situational awareness for upcoming flooding episodes, along with a discussion of how an ensemble-based approach could be explored to address forecast model error and uncertainty.
\end{abstract}

Corresponding author address: Jonathan L. Case, ENSCO, Inc./SPoRT Center, 320 Sparkman Dr., Room 3000 B, Huntsville, AL 35805. E-mail: Jonathan.Case-1@nasa.gov 


\section{Introduction}

Tropical cyclones (TCs) present a number of hazards to impacted coastal and inland populations, including damaging winds, storm surge along the coast, tornadoes, and extensive inland freshwater flooding. The severity of inland flooding depends on many factors such as (i) storm motion (that affects storm total rainfall) determined by atmospheric steering currents (Hall and Kossin 2019), (ii) extratropical transition and downstream impacts (Liu and Smith 2016; Keller et al. 2019), (iii) local geography, topography, and/or urbanization (Fang et al. 2014; Zhang et al. 2018), and (iv) antecedent soil moisture conditions and how it can sustain or modulate inland tropical cyclones (Kellner et al. 2012; Nair et al. 2019; Zhang et al. 2019). Numerous factors can combine to produce prodigious rainfall amounts and historic flooding such as with Tropical Storm Allison (2001) and Hurricane Harvey (2017) in southeastern Texas (Fang et al. 2014; Emanuel 2017; Zhang et al. 2018; Brauer et al. 2020).

Several studies have examined extreme rainfall events in recent decades, comparing TC-associated rainfall to other sources of extreme rainfall such as from fronts and extratropical cyclones. Kunkel et al. (2012) used a century of cooperative gauge stations to examine heavy precipitation events (1-in-5-yr return period) related to fronts, extratropical cyclones and TCs, and mesoscale convective systems. They found that TCs were responsible for $13 \%$ of the extreme rainfall events and-along with frontal extreme precipitation-have statistically significant upward trends nationally in the conterminous United States (CONUS). Similarly, in the Carolinas, Knight and Davis (2007) identified TCs as being responsible for $15 \%$ of the rainfall during the hurricane season; these authors also noted how soil moisture deficits would increase in the southeastern United States if it were not for TC-related rainfall. Shepherd et al. (2007) determined that major hurricanes (category 3-5) were responsible for the most extreme rainfall episodes, but that general tropical depressions/ storms contributed the most to overall cumulative seasonal rainfall. Using the hurricane database [maintained the National Hurricane Center (NHC)] and rain gauge data, Barlow (2011) found that TCs have substantial influence on extreme rainfall events in the United States, even well inland away from the coast, but particularly in the eastern United States.

The role of antecedent soil moisture can be quite important in determining vulnerability to flooding as well as sustaining tropical cyclones inland. Villarini et al. (2014) examined $30 \mathrm{yr}$ of discharge data to identify the eastern United States and Midwest regions as most susceptible to inland TC flooding (as in Barlow 2011), but additionally they inferred the importance of antecedent soil moisture for the Midwest region. Sturdevant-Rees et al. (2001) found that both orographic enhancement and antecedent soil moisture played important roles in the substantial flooding over the central Appalachians associated with Hurricane Fran (1996). In their study of climate-change scenarios over Australia, Wasko and Nathan (2019) determined that antecedent soil moisture plays a more important role in modest flooding events whereas precipitation is the most important driver affecting flooding associated with extreme precipitation episodes. Wet antecedent soils also have been shown to help sustain and/or intensify post-landfall TCs, as in Tropical Storm Erin (2007) strengthening over westcentral Oklahoma on 19 August 2007 (Evans et al. 2011; Kellner et al. 2012), and the unnamed Louisiana tropical low of August 2016 that produced massive rainfall and flooding from a "brown ocean" effect (defined by Andersen et al. 2013), in which the saturated soil behaved as an underlying warm ocean surface (Nair et al. 2019).

Numerous studies have examined the trends in extreme TC rainfall events, including Knight and Davis (2009) who attributed a 5-10\% per decade increase in TC rainfall from 1972 to 2007 to storm wetness and frequency, but with little indication that storm duration was responsible for increased wetness. Contrary to Knight and Davis (2009), Hall and Kossin (2019) concluded that the average TC translation speed has decreased since the mid-20th century, owing to both slower movement and an increase in abrupt direction changes - contributing to positive trends in annualmean TC rainfall from 1948 to 2017. Lau et al. (2008) found that $>50 \%$ of the observed trend in TC rainfall can be explained by the increased warm pool area (i.e., sea surface temperatures $>28^{\circ} \mathrm{C}$ ) in the north Atlantic basin. Meanwhile, Aryal et al. (2018) did not find statistically significant trends in magnitude nor frequency of TC-related floods using stream and rain gauge measurements; however, they did note that the North Atlantic Oscillation plays a significant role in TC-related extreme rainfall along the United States East Coast, whereas the El Niño/Southern Oscillation was most strongly linked to TC rainfall in Texas. In the northeastern United States, Huang et al. (2018) identified TCs as being responsible for nearly half 
of all extreme precipitation events post-1996, which were associated with the warm phase of the Atlantic Multidecadal Oscillation, higher total column water vapor, and potentially weaker steering currents. The authors further noted that the post-1996 extreme rainfall increases exceeded those that occurred in the previous warm phase of the Atlantic Multidecadal Oscillation from 1928 to 1962. Additionally, attribution studies have argued that anthropogenic contributions may be playing a role in recent extreme TC-related rainfall events (Wang et al. 2016; van Oldenborgh et al. 2017; Wang et al. 2018); however, attribution is not the focus of this paper.

Among recent Atlantic basin TCs that produced extreme rainfall, Emanuel (2017) used a physics-based risk model to assess the future probability of extreme rainfall from Hurricane Harvey. Several studies have examined the unusual track and intensity changes of Hurricane Joaquin from 2015 (Hendricks et al. 2018; Alaka et al. 2019; Miller and Zhang 2019), as well as conducted sensitivity tests to isolate the environmental factors responsible for its behavior and subsequent prodigious rainfall in South Carolina (Marciano and Lackmann 2017). Galarneau and Zeng (2020) provided a detailed synoptic analysis of Hurricane Harvey and examined the sensitivity of Harvey's track, intensity, and rainfall to antecedent soil moisture conditions through numerous simulation experiments. Kunkel and Champion (2019) identified Hurricanes Harvey (ranked first) and Florence (ranked seventh) as among the TCs that led to the largest area-averaged, multiday precipitation events, while also considering other phenomena such as fronts, extratropical cyclones, and atmospheric rivers. Paerl et al. (2019) suggested a regime shift has occurred in coastal North Carolina, leading to increased high rainfall from TCs-with a focus on Hurricanes Floyd (1999), Matthew (2016), and Florence (2018).

This manuscript examines four recent TCassociated extreme rainfall and flooding events in the United States from a soil moisture response perspective: Hurricane Joaquin (2015)-related flooding in South Carolina; Hurricane Harvey (2017) in southeastern Texas; Hurricane Florence (2018) in North Carolina; and Tropical Storm Imelda (2019), again in southeastern Texas. The objective of this article is to demonstrate how an observations-driven land surface model (LSM) and derived output can provide insight into the magnitude of the rainfall events based on soil moisture responses and the historical context of the soil moisture. Climatological and real-time soil moisture analyses are applied to quantify the modeled soil moisture response due to the extreme rainfall associated with each storm. Further, a technique is proposed for generating predicted soil moisture percentiles in order to contextualize potential future flooding events. The remainder of this paper is organized as follows: section 2 describes the datasets and methods used to analyze soil moisture responses; section 3 summarizes the four TC extreme rainfall events presented in this paper; section 4 provides analyses of soil moisture responses and percentiles associated with each TC flooding event; and a summary and conclusions are given in section 5 .

\section{Data and methods}

\section{a. Tropical cyclone tracks and rainfall analyses}

The best-track geographical information system (GIS) shapefile data were obtained from the NHC for each event. Characteristics of interest include the 6-h track position, intensity, and wind swath radii information. These datasets are available online at www.nhc.noaa.gov/gis/. Gauge-corrected, radar-based hourly quantitative precipitation estimates (QPEs) from the Multi-Radar Multi-Sensor (MRMS; Zhang et al. 2016) product is summed for the duration of each multiday event to generate storm-total rainfall.

\section{b. NASA Land Information System and the SPoRT-LIS}

Climatological and real-time output from a unique configuration of the NASA Land Information System (LIS), as developed and managed by the NASA Shortterm Prediction Research and Transition (SPoRT) Center (Jedlovec 2013), were used for this analysis. The NASA LIS is a high-performance land surface modeling and data assimilation system that can be used to run a variety of LSMs through the integration of satellitederived datasets, ground-based observations, and model reanalyses to characterize land surface states and fluxes (Kumar et al. 2006; Peters-Lidard et al. 2007). The LIS can run LSMs regionally or globally with a grid spacing as fine as $1 \mathrm{~km}$ (or finer, depending on available soil and land use classification databases) by using scalable, high-performance computing and data management technologies. The LIS features an ensemble Kalman filter algorithm (Evensen 2003) to conduct land surface data assimilation (Kumar et al. 2008, 2009) for a variety of datasets and variables such as soil moisture, 
land surface temperature, and snow (e.g., Liu et al. 2013). The system also supports an optimization and uncertainty analysis for calibrating LSM parameters to observations (Santanello et al. 2013). In addition to operating in offline (uncoupled) mode, the LIS has been coupled to the Weather Research and Forecasting (WRF) model (Kumar et al. 2007) for numerical weather prediction (NWP) research applications as part of the NASA unified-WRF modeling framework (Peters-Lidard et al. 2015) to enhance land-atmosphere studies within WRF.

The SPoRT Center has developed an in-house configuration of the LIS (hereafter SPoRT-LIS) for use in experimental operations by both domestic and international weather forecasters (Zavodsky et al. 2013; Case 2016; Case and Zavodsky 2018; McDonough et al. 2018). The SPoRT-LIS is an observations-driven, historical and real-time instantiation of the Unified Noah LSM (hereafter Noah LSM; Chen and Dudhia 2001; Ek et al. 2003) over a full CONUS domain (extent of SPoRT-LIS domain as displayed within AWIPSII is shown in Fig. 1 from 1500 UTC 26 September 2016). The SPoRT-LIS provides modeled soil moisture estimates at approximately $3-\mathrm{km}$ horizontal grid spacing over a $2-\mathrm{m}$ deep soil column, and has received favorable validation metrics for regional applications (McDonough et al. 2018). Early research-to-operations activities with previous iterations of the SPoRT-LIS involved initializing the WRF model with SPoRTLIS analyses to help improve local NWP modeling, primarily during the warm-season months (Case et al. 2008, 2011).

The basis of the SPoRT-LIS is a 33-yr modeled soil moisture climatology spanning 1981-2013, which is extended to the present time and forced by atmospheric analyses from the operational North American Land Data Assimilation System-Phase 2 (NLDAS-2; $\mathrm{Xia}$ et al. 2012). The real-time gap in NLDAS-2 atmospheric forcing input for the SPoRT-LIS is bridged by incorporating forcing from the National Centers for Environmental Prediction (NCEP) Global Data Assimilation System (GDAS; Wang et al. 2013) in combination with hourly MRMS QPE. The real-time component of the SPoRT-LIS updates on a 6-h cycle following the initialization schedule and availability of surface flux output files from the GDAS/Global Forecast System (GFS; Zhou et al. 2019) NWP model. Besides the minimal data latency, another unique feature of SPoRT-LIS is the incorporation-since 2012 - of daily, real-time satellite retrievals of green vegetation fraction (GVF) from the NOAA/National Environmental Satellite, Data, and Information Service global 4-km resolution product, derived from the Visible Infrared Imaging Radiometer Suite (VIIRS) instrument aboard the Suomi-National Polar-orbiting Partnership and the Joint Polar Satellite System satellites (Vargas et al. 2015).

The 33-yr soil moisture climatology also provides the database for near real-time, 0-2-m soil moisture percentiles (Zavodsky et al. 2016; Case and Zavodsky 2018). The 33-yr soil moisture climatology consists of daily 0-2-m relative soil moisture (RSM) values, where the RSM is the ratio of the modeled volumetric soil moisture $(\theta)$ between the wilting and saturation reference values for a given soil texture:

$$
R S M=\left(\frac{\theta-\theta_{\text {wilt }}}{\theta_{\text {sat }}-\theta_{\text {wilt }}}\right) \times 100 \% .
$$

The RSM is our preferred method for examining the model layered soil water content, because it normalizes the volumetric soil moisture based on the specified characteristics of each unique soil texture classification (sand-silt-clay composition). The RSM essentially depicts the percentage of water available to transpiration within the defined root zone of the vegetation type. Urban areas are masked out in the RSM field because the Noah LSM hard-codes a narrow dynamic range of $\theta$ for urban grid points.

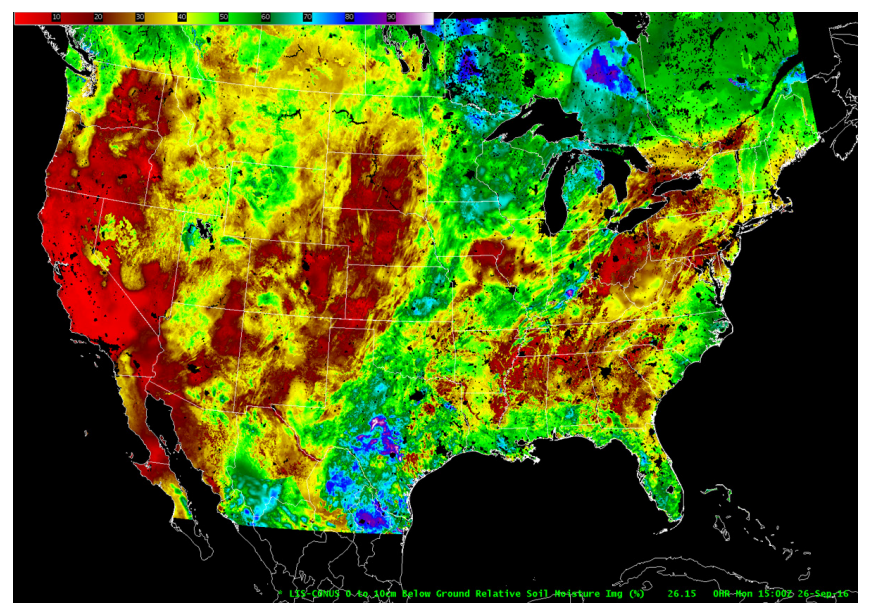

Figure 1. Depiction of SPoRT-LIS CONUS realtime domain of $0-10-\mathrm{cm}$ relative soil moisture (RSM) from 1500 UTC 26 September 2016, as displayed within AWIPS-II at the NOAA/NWS forecast office in Huntsville, AL. Click image for a full-resolution version; this applies to all figures and hereafter. 
Daily archived 0-2-m RSM values at each grid point from the 1981 to 2013 database are grouped together for each county of the CONUS to form a unique histogram for every day of the year, resulting in approximately $10^{6}$, or about a million unique soil moisture distributions comprising the climatology. The present-day 0-2-m RSM values are then compared to the unique daily county climatology to obtain a percentile at each model grid point for a given day. The currentday, county-mean percentiles are compared to historical distributions to place the present-day conditions into context to determine how wet, dry, or normal the soil conditions are for the specific time of year-similar to that described in Xia et al. (2014).

The daily SPoRT-LIS climatology was borne partly out of an operational need for soil moisture percentile values because anomalies of input fields represented by percentiles are a standard component of drought analysis used by the United States Drought Monitor (USDM; Svoboda et al. 2002). Working closely with NOAA/National Weather Service (NWS) collaborators via formal and informal assessments of SPoRT-LIS products, feedback determined that percentile data would be most appropriate for effective drought analysis. Additionally, other fields such as changes in soil moisture on weekly, monthly, seasonal, and annual timescales were recommended and implemented to better enhance situational awareness of drought conditions. The advantage of low-latency data and the incorporation of near real-time datasets such as VIIRS GVF and MRMS precipitation ensures greater accuracy in flash drought or flood situations, especially in locations of the southeastern United States that experience a relatively rapid-response hydrologic cycle.

Even though the use of SPoRT-LIS for drought analysis purposes is relatively straightforward, the use for its opposite (pluvial analysis) has been slower to evolve. The Huntsville NWS began investigating this application of the data after the passage of Tropical Storm Lee in September 2011, which failed to produce the expected flooding in the area, despite widespread rainfall of $200+\mathrm{mm}(\sim 8+$ in; White et al. 2017). This resulted in the development of thresholds of soil moisture and rainfall that were conducive to flooding, although the method was somewhat subjective. The latest iteration of utilizing soil moisture variables to assess the threat for flooding has moved into the machine-learning phase, involving the application of long short-term memory neural networks to assess flood threat in a more objective way (White et al. 2020).
Furthermore, the use of various soil moisture parameters for operational applications from fog forecasting in the northeastern United States to the threat for blowing dust in the Great Plains has been communicated to NASA SPoRT via collaborative forecast offices, although those have yet to be documented in the literature.

\section{Tropical cyclone flooding events}

Figure 2 summarizes the TC tracks for each storm analyzed, along with cyclone intensity and wind threshold swaths. A common theme among each of these extreme flood-producing TCs is the occurrence of a looping (Hurricane Joaquin in panel a), sudden directional change (Hurricanes Joaquin, Harvey, and Tropical Storm Imelda in panels a, b, and d), and/or slowing of the forward motion (Hurricanes Harvey and Florence in panels b and c). In the case of Joaquin, its initial translational speed was quite slow while to the east of Florida, which was followed by a southwestward motion toward the eastern Bahamas, then an unusual looping motion (see Miller and Zhang 2019) followed by a northeastward track. Both Alaka et al. (2019) and Miller and Zhang (2019) studied the forecast uncertainty, the unusual track evolution of Hurricane

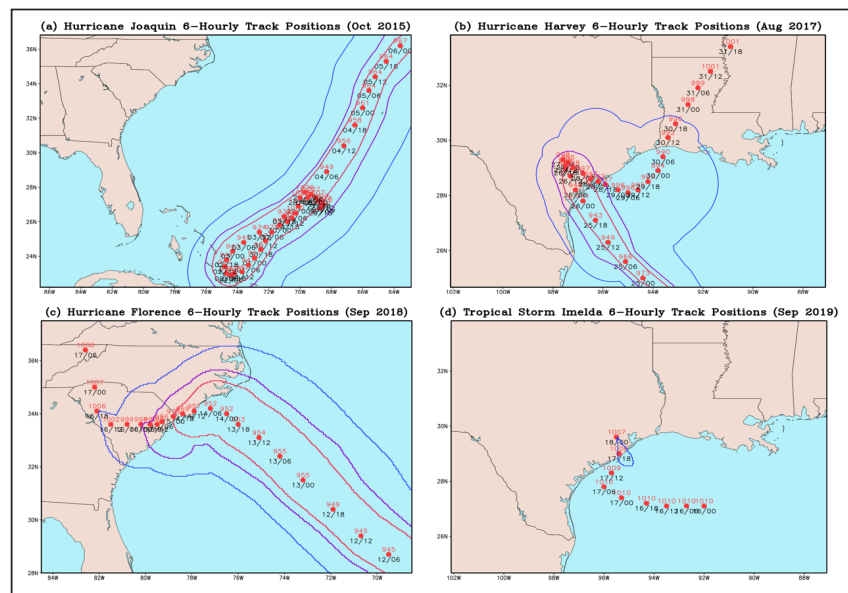

Figure 2. Six-hourly track positions and mean sea level pressure for each storm presented in this paper: (a) Hurricane Joaquin (2015), (b) Hurricane Harvey (2017), (c) Hurricane Florence (2018), and (d) Tropical Storm Imelda (2019). The outer blue lines indicate tropical storm force wind extent; the inner purple lines depict $25.7-\mathrm{m} \mathrm{s}-1(50 \mathrm{kt})$ wind extent; and the inner red lines show the hurricane force wind extent. The best-track GIS shapefile data were obtained from the National Hurricane Center, available online at www. nhc.noaa.gov/gis/. 


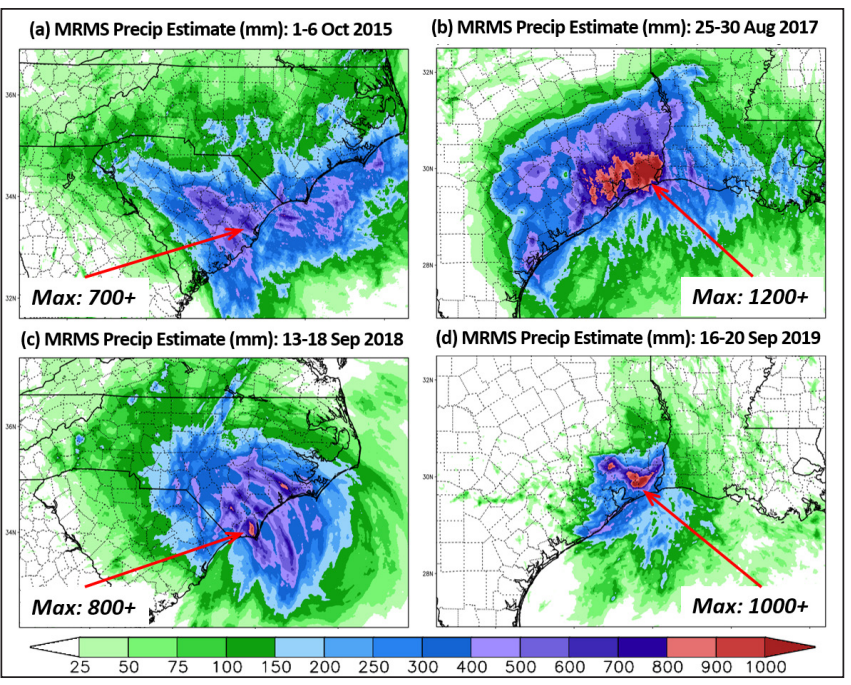

Figure 3. Storm total rainfall derived from the MRMS gauge-corrected radar QPEs for each tropical cyclone studied in this paper: (a) Hurricane Joaquin for 1-6 October 2015, (b) Hurricane Harvey for 25-30 August 2017, (c) Hurricane Florence for 13-18 September 2018, and (d) Tropical Storm Imelda for 16-20 September 2019.

Joaquin, and its interactions with synoptic steering flow and a trough in the southeastern United States. Among these four events, only Tropical Storm Imelda failed to become a major hurricane and, in fact, barely reached tropical storm intensity immediately prior to landfall in southeastern Texas.

The total accumulated QPEs of each storm consist of very large areal footprints of heavy rainfall $>200 \mathrm{~mm}$ ( $~ 8$ in), typically including a dozen or more affected counties (Fig. 3). Hurricane Harvey (2017) was the most substantial event, featuring an exceptionally large area of heavy to extreme rainfall of $200-400+\mathrm{mm}$ extending from near Corpus Christi (where Harvey made landfall) to southwestern Louisiana, and extending several counties inland. Maximum estimated rainfall was $>700 \mathrm{~mm}$ in each event, with the highest rainfall totals occurring in southeastern Texas associated with Hurricane Harvey (>1200 mm; Fig. 3b) and Tropical Storm Imelda (>1000 mm; Fig. 3d); Tropical Storm Imelda had the smallest footprint of exceptional rainfall among these four TCs.

A brief overview of the synoptic setup for each tropical cyclone is presented in Figs. 4 and 5 at select times when each cyclone was substantially impacting coastal and inland regions with flooding rainfall. Among the four studied, Joaquin was the most unique $\mathrm{TC}$ as it did not directly impact the coast. A plume

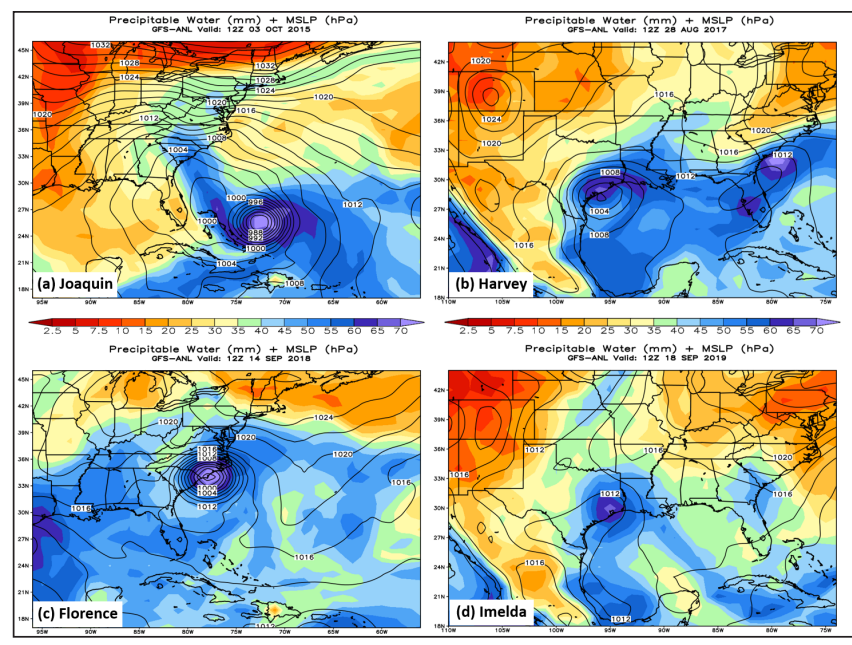

Figure 4. Global Forecast System (GFS) model analyses of precipitable water (mm; shaded) and mean sea level pressure (hPa; contours) at select times during each tropical cyclone rainfall event: (a) Hurricane Joaquin at 1200 UTC 3 October 2015, (b) Hurricane Harvey at 1200 UTC 28 August 2017, (c) Hurricane Florence at 1200 UTC 14 September 2018, and (d) Tropical Storm Imelda at 1200 UTC 18 September 2019.

of high precipitable water of $>50 \mathrm{~mm}$ extended from Joaquin to the Carolinas (Fig. 4a), and interacted with a deep, negatively tilted trough over the southeastern United States (Fig. 5a). According to the simulation sensitivity results in Marciano and Lackmann (2017), Joaquin acted to enhance the intensity of the jet streak, trough sharpness, and subsequent extreme rainfall amounts through its upper-level diabatic outflow, and therefore could be considered a type of predecessor rain event (i.e., Galarneau et al. 2010). Meanwhile, as Hurricane Harvey stalled near the southeastern Texas coast, a large area of precipitable water at 50$60+\mathrm{mm}$ resided over much of southeastern Texas and Louisiana, with an associated pressure trough/weak frontal boundary extending northward to the Midwest (Fig. 4b). A significant trough evident in the $250-\mathrm{hPa}$ geopotential height and $700-\mathrm{hPa}$ temperature fields to the northeast of Harvey over the western Great Lakes (Fig. 5b) was unable to influence the near stationarity of Hurricane Harvey on 28 August 2017, as Harvey did not begin to lift northeastward out of the region until after 30 August. The landfall of Hurricane Florence (2018) in the Carolinas was accompanied by a large symmetric maximum in precipitable water of $60+$ mm (Fig. 4c) beneath a broad area of upper-level high pressure across the eastern United States (Fig. 5c) with weak steering flow (not shown); therefore, the forward 


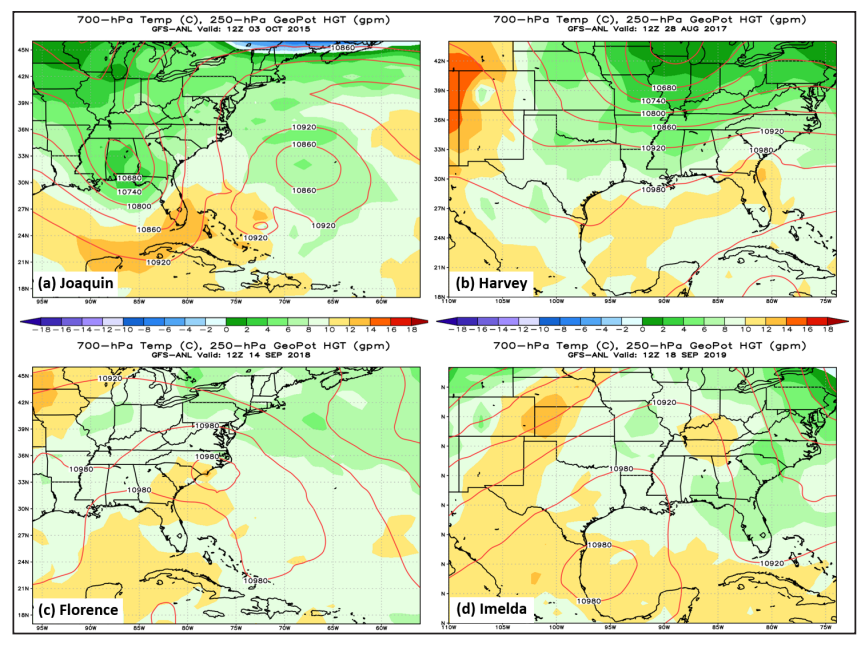

Figure 5. Same as Fig. 4 except for $700-\mathrm{hPa}$ temperature $\left({ }^{\circ} \mathrm{C}\right)$ and $250-\mathrm{hPa}$ geopotential height $(\mathrm{m})$.

progress of Florence slowed, and extreme rainfall resulted. Similarly, Imelda and its accompanying high precipitable water maximum of $>60 \mathrm{~mm}$ (Fig. $4 d$ ) developed under a broad area of upper-level high pressure extending from Texas to the Great Lakes (Fig. 5d), and it just managed to reach tropical storm strength prior to landfall in southeastern Texas. The next section examines the impact of these rainfall events on the modeled soil moisture analyses and compares the preand post-storm soil moisture conditions to the 19812013 SPoRT-LIS climatological database.

\section{Analysis and discussion}

\section{a. Soil moisture response to rainfall}

The impacts of the total rainfall from each TC on the resulting SPoRT-LIS 0-100-cm RSM (upper-half of Noah LSM soil column) are summarized in Fig. 6 for Hurricanes Joaquin, Harvey, and Florence, and Tropical Storm Imelda, respectively. The post-storm $0-100-\mathrm{cm}$ RSM results are presented because the upper-half of the Noah LSM column is more responsive on shorter time scales to significant rainfall and/or drying episodes compared to the $100-200-\mathrm{cm}$ layer, which adjusts to meteorological forcing on the order of months to years. Hourly animations also are available via the links provided in the Fig. 6 caption to capture the overall breadth and the rapidity by which the soils moisten in response to each extreme rainfall event. For each event, there is an exceptional transition from anomalously dry conditions in many locations of the pre-storm environment to record wetness following the event, which may have acted to slightly delay the onset of the inevitable flooding. Additionally, an interesting future research topic could focus on the frequency and role of extreme TC rain events serving to end regional drought episodes.

Following the extreme rainfall indirectly attributed to Hurricane Joaquin and its interaction with a midlatitude trough (see Marciano and Lackmann 2017), much of central South Carolina had 0-100-cm RSM values $>70 \%$, with areas closer to the coast and along the coastal plain of North Carolina at $>80 \%$ (Fig. 6a). Further inland, final $0-100-\mathrm{cm}$ RSM was $>65 \%$ in northeastern Georgia and along the front-range of the Appalachians in western North Carolina. Meanwhile, conditions remained quite dry across south-central Georgia - having largely missed the Joaquin-associated rainfall (refer to Fig. 3a), with many areas experiencing $0-100-\mathrm{cm}$ RSM values of $<20-30 \%$ at 0000 UTC 6 October 2015.

After Hurricane Harvey's exceptional rainfall in southeastern Texas and southwestern Louisiana, a large footprint of $0-100-\mathrm{cm}$ RSM $>80 \%$ was found from the Houston metropolitan area northeastward to western Louisiana, with localized areas $>90 \%$ along the state border (Fig. 6b). A large portion of south-central to southeastern Louisiana also had 0-100-cm RSM $>80 \%$. Outside of the Hurricane Harvey rainfall area (Fig. 3b), soil moisture remained extremely dry across southern and central Texas, with many areas close to the wilting point in the top one meter $(<10 \% \mathrm{RSM})$. A sharp gradient in 0-100-cm RSM delineates the left/northern/ western edge of Harvey's rainfall footprint.

Following Hurricane Florence in the Carolinas, the SPoRT-LIS 0-100-cm RSM again depicted values $>70 \%$ across a large portion of southern and eastern North Carolina and adjacent portions of eastern South Carolina (Fig. 6c). A relative maximum in $0-100-\mathrm{cm}$ RSM of $>65 \%$ also occurred along the Appalachian Front Range from western North Carolina into southcentral Virginia. A few locally drier pockets of $<50 \%$ RSM remained across the Piedmont of central North Carolina into southeastern Virginia. More prevalent post-Florence dryness existed across the southwestern half of South Carolina into Georgia, where these areas largely missed out on the rainfall event (refer back to Fig. 3c).

A much more localized soil moisture response occurred in southeastern Texas, as seen in Fig. 6d, associated with Tropical Storm Imelda owing to its smaller rainfall footprint (Fig. 3d). However, despite 


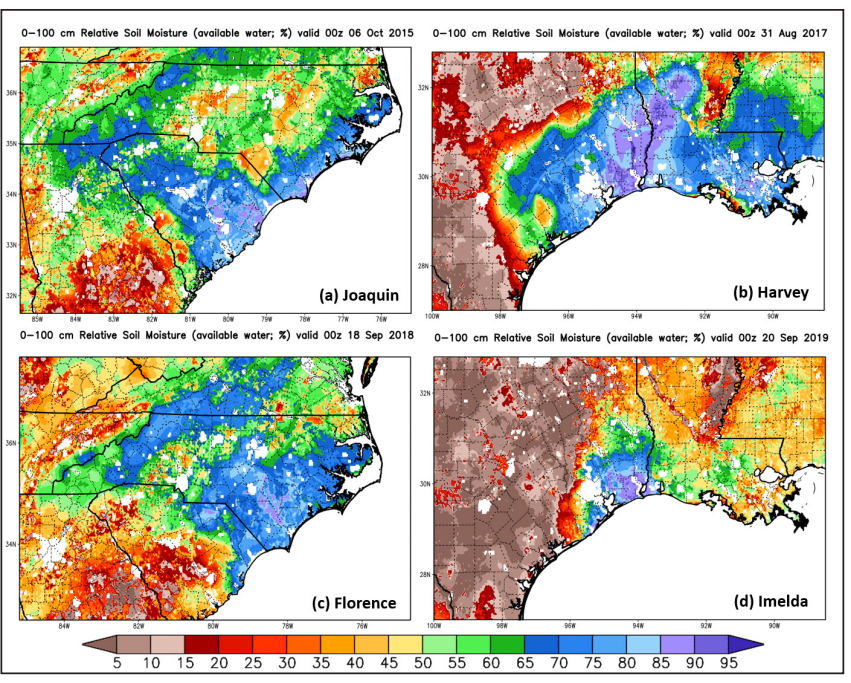

Figure 6. Final SPoRT-LIS 0-100-cm RMS analyses following each tropical cyclone rainfall event presented in this manuscript: (a) Hurricane Joaquin valid 0000 UTC 6 October 2015, (b) Hurricane Harvey valid 0000 UTC 31 August 2017, (c) Hurricane Florence valid 0000 UTC 18 September 2018, and (d) Tropical Storm Imelda valid 0000 UTC 20 September 2019. Urban and water pixels are masked out and depicted as white. Animations of evolving hourly $0-100-\mathrm{cm}$ RSM analyses with overlaid MRMS precipitation contours for each multi-day event are available online at the following links:

Hurricane Joaquin at http://nwafiles.nwas.org/jom/ articles/2021/2021-JOM1-figs/Fig_06a.gif

Hurricane Harvey at http://nwafiles.nwas.org/jom/ articles/2021/2021-JOM1-figs/Fig_06b.gif

Hurricane Florence at http://nwafiles.nwas.org/jom/ articles/2021/2021-JOM1-figs/Fig 06c.gif

Tropical Storm Imelda at http://nwafiles.nwas.org/jom/ articles/2021/2021-JOM1-figs/Fig_06d.gif.

the smaller area of impact, the marked contrast in the resulting soil moisture analysis is perhaps most dramatic with this event. Within the region of intense rainfall from the Houston metropolitan area to the Louisiana border, the final $0-100-\mathrm{cm}$ RSM values at 0000 UTC 20 September 2019 were generally between 80 and $90 \%$. Outside of the rainfall region, soil moisture was exceptionally dry and approached the wilting point, especially across central Texas where large pockets of $0-100-\mathrm{cm}$ RSM were $<5 \%$. The post-storm soil moisture contrast was not as stark on the eastern edge of Imelda's rainfall, yet a sharp transitional gradient still existed across southwestern and central Louisiana.

\section{b. Pre- and post-storm soil moisture relative to climatology}

To help contextualize the SPoRT-LIS soil moisture conditions relative to "normal" values, we next examine the pre- and post-storm soil moisture percentiles for the entire 0-2-m soil column, derived from the daily 1981-2013 county-based climatologies as previously described. In each case, the pre-storm antecedent soil moisture conditions were anomalously dry for the geographical regions impacted by the heavy rainfall (Fig. 7), with the exception being portions of southeastern Texas and southwestern Louisiana prior to Hurricane Harvey (Fig. 7b). In Figs. 7 and 8, the dry soil moisture percentiles are colorized according to proxy values for the USDM drought categories, using communityrecognized thresholds of the 30th, 20th, 10th, 5th, and 2nd percentiles to represent drought categories D0 to D4, respectively (Xia et al. 2014). Similarly, the mirror wet analogs representing anomalously wet conditions are given by the 70th, 80th, 90th, 95th, and 98th percentiles. The median percentiles in the $30-70 \%$ range are assigned a nominal gray shading in the plots.

The pre-storm soil moisture percentiles were the most anomalously dry over the Carolinas and Georgia prior to Hurricane Joaquin (Fig. 7a) and Florence

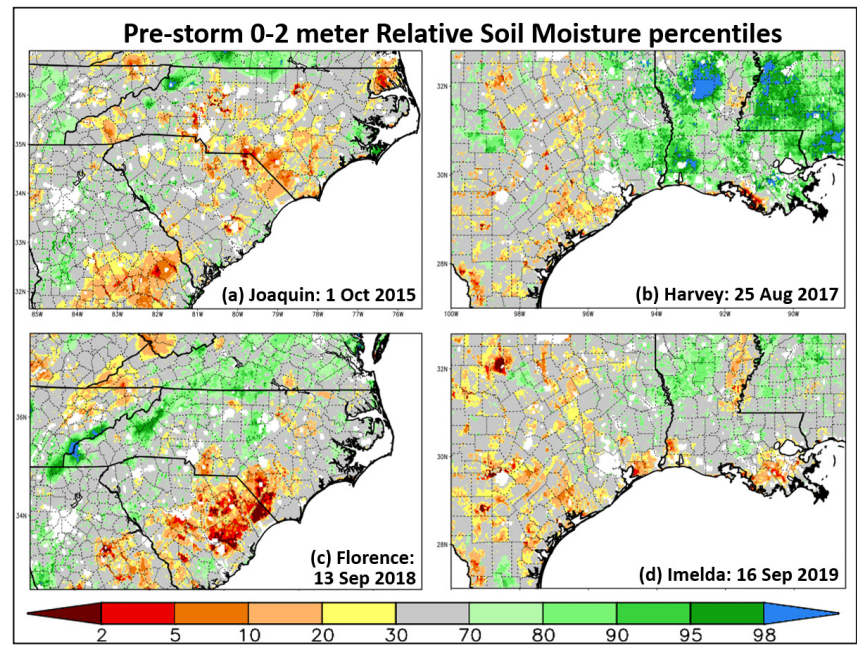

Figure 7. Distribution of SPoRT-LIS total-column (0-2 m) RSM percentiles in the pre-storm environment of each tropical cyclone, valid on (a) 1 October 2015 prior to Hurricane Joaquin rainfall, (b) 25 August 2017 prior to Hurricane Harvey rainfall, (c) 13 September 2018 prior to Hurricane Florence rainfall, and (d) 16 September 2019 prior to Tropical Storm Imelda rainfall. Urban and water pixels are masked out and depicted as white. 
rainfall episodes (Fig. 7c). In fact, prior to the Joaquinassociated rainfall event, the USDM classified many areas of the Carolinas in the D0 (anomalously dry) to D2 range (severe drought; see Fig. 1 of Case 2016). Only pockets of D0 were analyzed prior to Hurricane Florence, primarily over South Carolina (not shown). Unusually dry soil conditions also prevailed to the south and west of the Houston metropolitan area before Hurricane Harvey (Fig. 7b) and between Houston and the Louisiana border in far southeastern Texas prior to Tropical Storm Imelda (Fig. 7d). Scattered pockets of D0/D1 were analyzed in the weekly USDM over south-central Texas prior to Harvey; however, more widespread moderate-to-severe drought conditions were depicted prior to Imelda, primarily in southern and central Texas and west of a meridional line intersecting the Houston metropolitan area (not shown). The 0-2$\mathrm{m}$ SPoRT-LIS percentiles do indicate anomalously dry soil moisture conditions from the Houston metropolitan area to southwestern Louisiana prior to Tropical Storm Imelda, with values below the 20th percentile in this small region that was most substantially impacted by Imelda's rainfall (refer to Figs. 3d, 6d, and 7d).

The post-storm 0-2-m percentiles in Fig. 8 quantify the soil wetness in relation to the daily, countybased climatological distributions from the 1981 to 2013 database. The largest geographical coverage of percentiles at the wet tail of the historical distribution occurred following Hurricane Harvey (Fig. 8b). Much of southeastern Texas and southern/western Louisiana experienced soil moisture above the 98th percentile for this time of year. Substantial areas of post-storm soil moisture (above the 98th percentile) also were found in over half of South Carolina and coastal portions of North Carolina after Hurricane Joaquin-associated rainfall (Fig. 8a), with a similarly oriented footprint and coverage of $\geq 98$ th percentiles following Hurricane Florence in southeastern North Carolina (Fig. 8c). A much smaller area of percentiles $\geq 98$ th occurred in far southeastern Texas after Tropical Storm Imelda, generally confined between the Houston metropolitan area and the Louisiana border (Fig. 8d). The counties labeled in each panel of Fig. 8 are used in subsequent analyses in the next three subsections to highlight the temporal evolution of soil moisture responses leading up to, and following, each TC extreme rainfall event.

\section{c. Daily soil moisture evolution during Hurricane Harvey}

Given the exceptional magnitude of Hurricane Harvey (in both total rainfall amount and geographical coverage), we now present a day-by-day evolution of the total-column soil moisture responses for two select counties in southeastern Texas that were heavily impacted by the extreme rainfall: Harris County (representing the Houston area) and Jefferson County (representing Beaumont/Port Arthur). Figure 9 shows the daily 1981-2013 histograms of 0-2-m RSM from 26 to 29 August (gray bars and colored reference percentiles), along with the actual county-averaged 0-2m RSM values for 2017 (given by bold dashed lines). The reference and daily values with corresponding percentiles are listed in the upper-right of each panel. For Harris County, Texas, the climatological histograms of 0-2-m RSM depict a positively skewed distribution with a frequency peaking in the $30-40 \%$ range and a tail extending toward higher values.

Rainfall began in earnest during the evening of 25 August 2017 in Harris County, and by 1200 UTC 26 August 2017 the mean of all SPoRT-LIS 0-2-m RSM

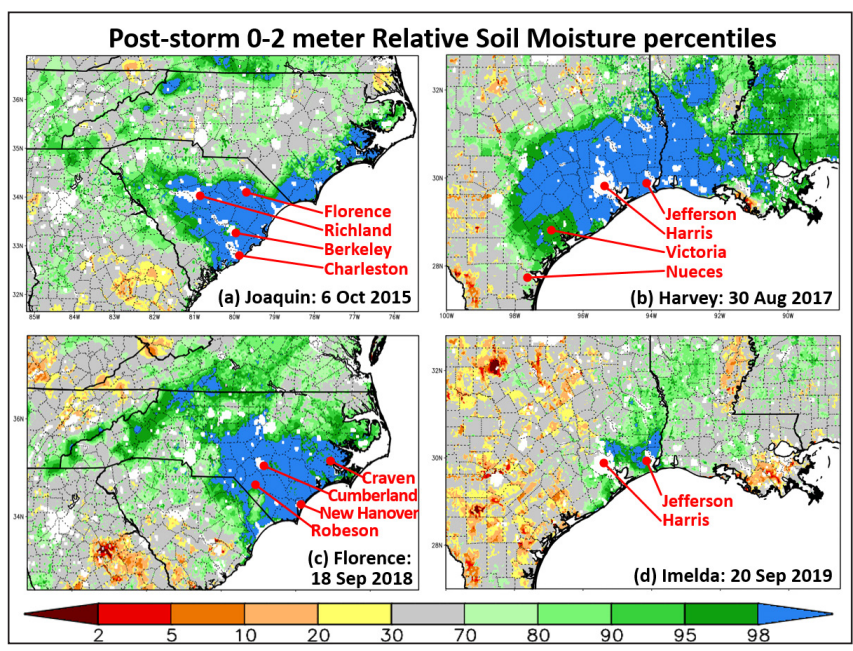

Figure 8. Distribution of SPoRT-LIS total-column relative soil moisture percentiles in the post-storm environment of each tropical cyclone valid on (a) 6 October 2015 following Hurricane Joaquin rainfall, (b) 30 August 2017 following Hurricane Harvey rainfall, (c) 18 September 2018 following Hurricane Florence rainfall, and (d) 20 September 2019 following Tropical Storm Imelda rainfall. Locations of counties used in time series plots in Figs. 11 and 12 are labeled in each panel. Urban and water pixels are masked out and depicted as white. 


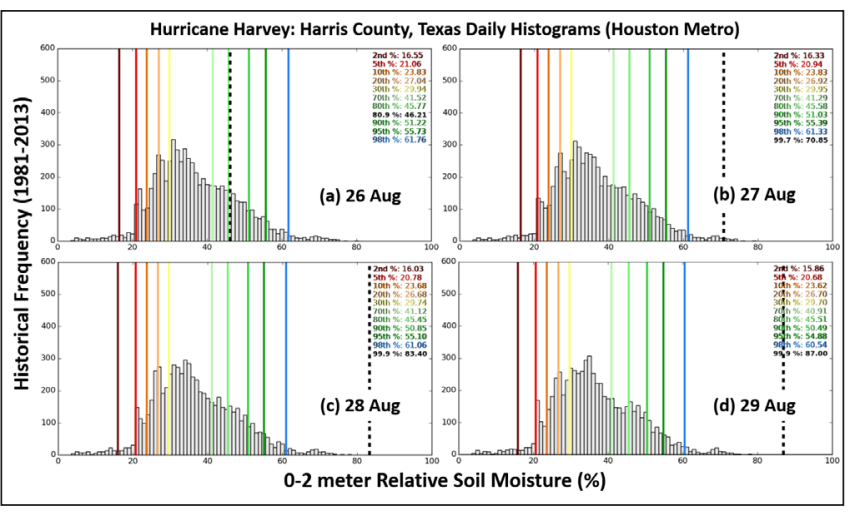

Figure 9. Historical histograms and 2017 daily mean 0-2-m RSM values for Harris County, TX, associated with the Hurricane Harvey rainfall event, valid on (a) 26 August, (b) 27 August, (c) 28 August, and (d) 29 August 2017. Gray bars represent the 33-yr frequency of daily 0-2-m RSM values from 1981 to 2013 for all SPoRT-LIS grid points within Harris County; vertical colored lines and corresponding legend text are reference percentiles for proxy drought categories (2nd, 5th, 10th, 20th, and 30th percentiles) and mirror wet analogs (70th, 80th, 90th, 95th, and 98th percentiles); vertical dashed lines are the present-day, county-wide mean values evaluated daily at 1200 UTC, with the values denoted in the legend in black font.

grid points lying within Harris County yielded a value of 46.2, or the 80.9th percentile in the distribution (Fig. 9a). However, only a day later, as extremely heavy rainfall continued across Harris County, the countywide mean already reached the 99.7 th percentile (Fig. 9b), nearing the tail of the 1981-2013 distribution composed of individual SPoRT-LIS grid point values (not county-wide means, as denoted by the dashed line). By 28 August (Fig. 9c), the county mean 0-2-m RSM exceeded the tail of the historical histogram with a value of 83.4 - essentially at the 100th percentile. The incredible exceedance of the tail of the distribution only grew more impressive by 1200 UTC 29 August (Fig. 9d) as the county-wide mean 0-2-m RSM reached 87.0, indicating a near saturation of the 2-m column of the Noah LSM across the entire county. By comparison, following Tropical Storm Allison (2001), the county mean 0-2-m RSM for Harris county peaked at 67.9 on 10 June 2001 ( 96 th percentile, not shown).

Jefferson County, Texas, experienced a similar daily evolution in 0-2-m RSM to record levels, albeit delayed by a day from Harris County (Fig. 10). Jefferson County began the event at slightly elevated soil moisture levels on 26 August (Fig. 10a), with percentiles at 74.4. By 27 August, the total-column percentile reached 96.5 (averaged across the whole county, Fig. 10b), and then proceeded to reach the tail of the 1981-2013 distribution by 28 August (Fig. 10c) - exceeding it by 29 August (Fig. 10d). In fact, by 1200 UTC 30 August, the mean 0-2-m RSM across Jefferson County reached an exceptional value of 90.36 (not shown), which is even closer to a total-column saturation than in Harris County. [Following Tropical Storm Allison, the Jefferson County mean 0-2-m RSM peaked at 73.55, near the 96th percentile (not shown).] To achieve such high soil wetness within the Noah LSM is particularly noteworthy given that the model has free drainage at the bottom boundary and is not coupled to a groundwater model, such as its successor, the NoahMultiParameterization options (Noah-MP) LSM (Niu et al. 2011), which is run in the NOAA National Water Model.

\section{d. Residence time of post-storm wet soil anomalies}

Another way to analyze the time evolution of soil moisture anomalies is to examine time series of the county-averaged 0-2-m RSM percentiles from the previous subsection. Because the daily percentiles are derived from the seasonally varying soil moisture distributions, declines (increases) in percentiles are essentially declines (increases) relative to seasonal "normal," as expressed within the daily climatological probability density functions. The time series plots can serve to illustrate the residence time of anomalously wet soils following the extreme rainfall events. Of course, the post-storm longevity of wet soil anomalies is also dependent on subsequent precipitation episodes and the prevailing weather regime. However, convergence toward an approximate median soil moisture value

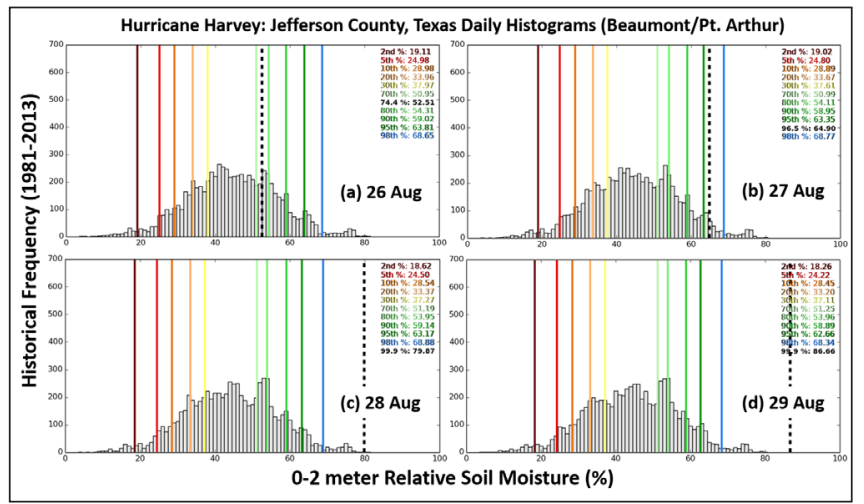

Figure 10. Same as in Fig. 9 except for Jefferson County, TX. 
should eventually occur given a typical weather/rainfall regime for a given county. The labeled counties in each panel of Fig. 8 are presented in this section to examine the pre- and post-storm soil moisture evolution during a period of several months on either side of the respective rainfall event.

Perhaps the clearest signal of pre- and post-storm soil moisture transition occurred in the select South Carolina counties associated with the Hurricane Joaquin rainfall. The selected counties ranged from coastal (Charleston) to central interior (Richland; Fig. $8 \mathrm{a}$ ), thereby capturing the representative variety of soil texture and land-use of the areas impacted by the heavy precipitation. Figure 11a shows that among these four sampled counties, pre-storm percentiles degraded from anomalously wet in May 2015 ( 70-90th percentiles) to anomalously dry during the summer and early fall (median values to as low as $\sim 10-20$ th percentiles) leading up to Joaquin. As stated above, some areas of South Carolina fell into moderate to severe drought categories preceding the Joaquin rainfall. All four counties experienced a sudden, dramatic transition to near-record wetness percentiles relative to the 19812013 climatologies following the heavy rainfall (early October, near the plot center), followed by a gradual decline in percentiles over the next several months. It took about 6 months for these counties to converge toward near-median percentile values after the sudden moistening took place. Periodic minor wetting events can be gleaned via the upticks in the time series.

In the Hurricane Harvey rainfall, four counties selected for time series analysis range from near landfall in Nueces and Victoria counties to the upper coast at Harris and Jefferson counties (Fig. 8b); the former two counties experienced markedly lower rainfall totals than the latter two counties. These counties generally had near-median soil moisture percentiles in the months leading up to Hurricane Harvey, but Nueces and Victoria counties drifted into the anomalously dry zone with $\sim 20$-30th percentiles immediately prior to Harvey (Fig. 11b). Harris and Jefferson counties experienced a substantial rainfall event in early August 2017, as noted by the sharp uptick to $\sim 80$ th percentile prior to the substantial percentile increases associated with Harvey a few weeks later. Nueces County only experienced a temporary wetting for about a month due to Hurricane Harvey before settling back down to the 30th percentile or lower, consistent with the much lower rainfall totals (Fig. 3b) and drier antecedent soil moisture. The other three counties all approached or exceeded record

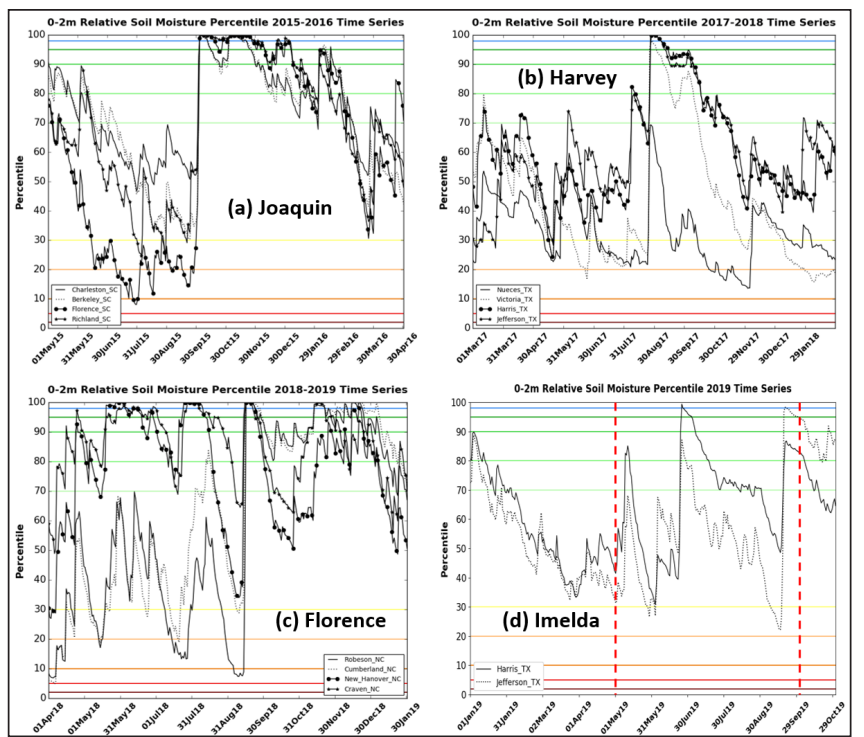

Figure 11. Time series plots of daily, county-averaged 0-2-m RSM percentiles associated with each significant tropical cyclone rainfall event: (a) Hurricane Joaquin (2015) for select counties in SC labeled in Fig. 8a, (b) Hurricane Harvey (2017) for select counties in southeastern TX labeled in Fig. 8b, (c) Hurricane Florence (2018) for select counties in eastern NC labeled in Fig. 8c, and (d) Tropical Storm Imelda (2019) for select counties in southeastern TX labeled in Fig. 8d. With the exception of Imelda in (d), the rainfall events are approximately in the center of each time series. The vertical red dashed lines in panel (d) denote the time period of the time series plot presented in Fig. 12.

percentiles following Harvey's rainfall, followed by steady decline in percentiles to near-median values over the next three months. The percentiles declined more rapidly in Victoria County, likely due to the overall lower rainfall totals and subsequent lack of rainfall events.

In general, the decline in anomalously wet soil moisture was more rapid following Harvey than postJoaquin in South Carolina, despite the monumental rainfall totals associated with Harvey. One potential contribution to the unexpectedly fast decline in totalcolumn soil moisture (especially for Harvey) is the free drainage at the bottom boundary of the Noah LSM. An important forthcoming sensitivity is to conduct a similar SPoRT-LIS simulation using Noah-MP in place of Noah to determine the impact of coupling an LSM to a groundwater model both during and following the substantial rainfall event, including a time series comparison of county-averaged rainfall to soil moisture response. The upward flux from the aquifer could 
significantly impact the rate of post-storm soil moisture decline and the resulting surface energy budget (e.g., Barlage et al. 2015), especially for extreme scenarios such as those studied herein. Additionally, the free drainage in the Noah LSM could have prevented the complete saturation of the overall RSM levels during Hurricane Harvey's (and the other tropical cyclones) active flooding periods. Future inter-comparisons between Noah and Noah-MP during Hurricane Harvey, including a detailed water budget analysis, will help reveal the impact of free drainage versus groundwater coupling on the associated evolution of deep-layer soil moisture.

A range of counties across southeastern North Carolina was chosen for temporal analysis within the footprint of Hurricane Florence's exceptional rainfall (Fig. 3c and Fig. 8c). The time series of these four counties depict markedly different antecedent soil moisture anomalies leading up to Hurricane Florence, with the coastal counties (New Hanover and Craven) generally having percentiles in the 70-90th range until the final month before Florence (Fig. 11c). Meanwhile, the counties further inland (Robeson and Cumberland) had consistently drier soils with large swings over relatively short time periods (median to slight dry anomalies). Interestingly, following the Hurricane Florence rainfall in mid-September, the two inland counties with lowest percentiles prior to the event remained at consistently higher percentiles following Florence over the next several months, whereas the coastal counties' percentiles declined to median levels fairly rapidly over the next two months. A combination of rainfall patterns and the prevailing soil texture could be responsible for the different behavior in soil moisture drying rates in these counties. It appears that frequent rainfall continued throughout Autumn 2018, as all four counties experienced unusually wet soils in the 80-98th percentile range.

A similar time series plot is given in Fig. 11d for Tropical Storm Imelda for Harris (Houston) and Jefferson County (Beaumont/Port Arthur) in southeastern Texas, which also were substantially impacted by Hurricane Harvey rainfall and subsequent flooding. A prolonged drying trend is seen during the first five months of 2019 down to percentiles in the 3050th range by May. A few substantial wetting events occurred in early May and especially late June, followed by another drying trend through September. Tropical Storm Imelda's rainfall hit in mid-September, with the sharpest increase in 0-2-m RSM percentile occurring in Jefferson County, increasing from near the 20th to the 98th percentile following the heavy rainfall. Harris County experienced substantially less rainfall with only a modest percentile increase from the $\sim 50$ th to $\sim 85$ th percentile (Fig. 11d).

\section{e. Toward forecast soil moisture percentiles: Tropical Storm Imelda example}

These analyses are useful and interesting from a post-event diagnosis; however, the SPoRT-LIS product may offer much more utility if it can provide forecast guidance of future soil moisture conditions and anomalies. Therefore, we are beginning to experiment with generating forecast SPoRT-LIS conditions and percentiles, initially using GFS model inputs, for computing future Noah LSM soil conditions. An example time series plot that depicts both historical and several days of predicted 0-2-m RSM percentiles for Harris and Jefferson County, Texas, is shown in Fig. 12. The time extent along the $\mathrm{x}$-axis of Fig. 12 corresponds to the date range between the vertical red dashed lines in Fig. 11d. The bold vertical dashed line in Fig. 12 denotes the initialization time of the GFS inputs that generated the forecast percentiles.

We can surmise from the forecast percentiles that the GFS model only slightly underestimated the precipitation for Harris County, Texas, as the forecast percentiles (red dotted line at $\sim 80$ th percentile) came in only slightly lower than the percentile analysis (solid black line at $\sim 85$ th percentile). However, in Jefferson County, Texas, which experienced the brunt of the extreme rainfall from Tropical Storm Imelda, the GFS model strongly underestimated the rainfall and its impact on the soils, as the forecast percentiles following the event (red dotted line with stars at $\sim 70$ th percentile) were substantially lower than the analysis-based values (sold black line with stars at $295-98$ th percentile). When placed in context with the historical soil moisture distributions, percentile differences of this magnitude can result in substantial variations in the degree of soil saturation and subsequent runoff and flooding if the LSM output is routed into hydrological models, especially for skewed climatological distributions. To amend the limitations of a single deterministic forecast scenario and its associated errors and uncertainties, an ensemble-based approach likely would provide more utility — offering a probabilistic approach for predicting future soil moisture conditions. Such a system could employ a "poor-man's" multi-model forcing approach, 


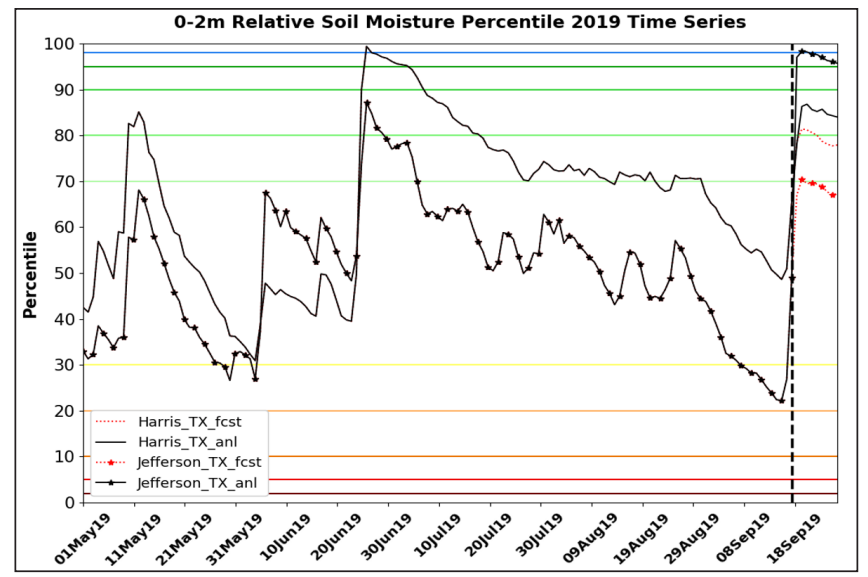

Figure 12. Time series plots of both SPoRT-LIS analysis and forecast $0-2-\mathrm{m}$ RSM percentiles for Harris and Jefferson counties in southeastern TX associated with Tropical Storm Imelda rainfall. The red dotted lines to the right of the vertical dashed line (aligned with 18 September) denote predicted county-averaged 0-2-m RSM percentiles from SPoRT-LIS utilizing quantitative precipitation forecasts and other meteorological forcing from the GFS model.

time-lagged ensembles from a single NWP model, and/or forcing driven by individual members of an operational ensemble modeling system such as the Global Ensemble Forecast System (Guan et al. 2015; Zhou et al. 2017) or the High Resolution Ensemble Forecast for shorter time scales. The SPoRT Center will be exploring these various ensemble forecast strategies for generating experimental predicted soil moisture conditions for value-added products in the areas of land surface modeling and hydrological applications.

\section{Summary and conclusions}

This paper presents how an observation-driven historical and real-time land surface modeling system can be applied to diagnose the soil moisture behavior associated with extreme TC rainfall events. Several land-falling TCs in recent years have impacted the United States and produced historic amounts of rainfall and flooding, four of which were highlighted in this paper: Hurricane Joaquin-associated rainfall in South Carolina; Hurricane Harvey in southeastern Texas and southwestern Louisiana; Hurricane Florence in (primarily) North Carolina; and Tropical Storm Imelda, again in southeastern Texas. Each of these four events featured sudden changes in the cyclone directional track and/or slowing of the forward motion that contributed substantially to the extreme rainfall totals. Hurricane Harvey and Tropical Storm Imelda produced the highest total precipitation maxima at $>1200$ and 1000 $\mathrm{mm}$, respectively, in southeastern Texas, followed by Hurricane Florence $(>800 \mathrm{~mm}$ ) and Hurricane Joaquin $(>700 \mathrm{~mm})$ in North and South Carolina, respectively. Hurricane Harvey also had the largest geographical footprint of extreme rainfall totals, placing it first among the largest area-averaged, multi-day precipitation episodes of any kind in the United States dating back to 1949 (Kunkel and Champion 2019).

Using historical and real-time output from the observations-driven SPoRT-LIS running the Noah LSM at $\sim 3-\mathrm{km}$ grid spacing across the CONUS, we presented how the modeled soil moisture responded to each multi-day rainfall event, typically transitioning from below-median/anomalously dry soils in the prestorm environment to record or near-record high soil wetness levels in the post-storm state. In each of the cases shown, some portion of the geographical areas impacted by the extreme rainfall experienced prestorm proxy drought conditions given by $0-2-\mathrm{m} \mathrm{RSM}$ soil moisture percentiles below the 20th percentile. These proxy drought conditions depicted by SPoRTLIS were reasonably consistent with the weekly USDM drought classification products. The post-storm conditions featured soil moisture that ranked above the 98th percentile relative to daily, county-based historical distributions from 1981 to 2013 across large geographical regions, except for Tropical Storm Imelda, where exceptionally high percentiles were confined to only a few counties in far southeastern Texas. By further dissecting the daily evolution of soil moisture over Harris and Jefferson County, Texas, during Hurricane Harvey, we quantified how quickly the soil converged toward a saturated state throughout the entire 2-m column. The gridded soil moisture averaged across these two counties far exceeded the tails of the 1981-2013 histogram distributions composed of individual grid point values, thereby further illustrating the exceptional nature of the event.

Time series analyses of county-averaged percentiles were presented to document soil moisture conditions leading up to each event, the abrupt pre- to post-storm transitions, and the residence time of the anomalously moist soils following each TC. Among the counties sampled, the Joaquin rainfall event had the most consistent behavior in soil moisture percentile trends in both the pre- and post-storm environments. The decline in soil moisture following Hurricane Harvey appeared 
to occur too rapidly in the counties that were impacted by record rainfall and flooding. It is hypothesized that the lack of coupling to a groundwater model in the Noah LSM may be responsible for the decline to nearmedian soil moisture values in only 3-4 months after the entire soil column was nearly saturated. Comparisons to future sensitivity simulations with the Noah-MP LSM that includes coupling to a groundwater model can help address this dilemma. Following Hurricane Florence, much of North Carolina experienced consistently above-normal rainfall during November and December 2018 (not shown) that kept soil moisture values above the 80th percentile.

Finally, Tropical Storm Imelda provided an opportunity to showcase a model-driven forecast versus analysis of soil moisture percentiles. Such a forecast product could help increase situational awareness for potential upcoming flooding events by contextualizing the projected soil moisture relative to the historical database. Incorporating soil moisture inputs into machine-learning models also can provide meaningful short-term guidance on streamflow and flooding potential for individual basins. Furthermore, an ensemble modeling method could be implemented to address uncertainties associated with deterministic quantitative precipitation forecasts of major flooding events, helping to provide a probabilistic approach to forecasting future soil moisture conditions and anomalies.

Acknowledgments. This research was funded by Dr. Tsengdar Lee of the NASA Science Mission Directorate's Earth Science Division in support of the SPoRT program at the NASA MSFC. Computational resources for this work were provided by the NASA Center for Computational Sciences at the NASA Goddard Space Flight Center. The authors greatly appreciate Dr. Pablo Santos, Mr. Patrick Burke, and an anonymous reviewer for their constructive suggestions that improved the manuscript. The authors also thank Dr. Erika Duran of the NASA SPoRT Center and Mr. Frank Alsheimer of the NWS Columbia, South Carolina, forecast office for reviews of the manuscript prior to submission. Mention of a copyrighted, trademarked or proprietary product, service, or document does not constitute endorsement thereof by the authors, ENSCO Inc., the SPoRT Center, the National Aeronautics and Space Administration, the National Oceanic and Atmospheric Administration, or the United States Government. Any such mention is solely for the purpose of fully informing the reader of the resources used to conduct the work reported herein.

\section{REFERENCES}

Alaka, G. J., Jr., X. Zhang, S. G. Gopalakrishnan, Z. Zhang, F. D. Marks, and R. Atlas, 2019: Track uncertainty in high-resolution HWRF ensemble forecasts of Hurricane Joaquin. Wea. Forecasting, 34, 1889-1908, Crossref.

Andersen, T. K., D. E. Radcliffe, and J. M. Shepherd, 2013: Quantifying surface energy fluxes in the vicinity of inland-tracking tropical cyclones. J. Appl. Meteor. Climatol., 52, 2797-2808, Crossref.

Aryal, Y. N., G. Villarini, W. Zhang, and G. A. Vecchi, 2018: Long term changes in flooding and heavy rainfall associated with North Atlantic tropical cyclones: Roles of the North Atlantic Oscillation and El Niño-Southern Oscillation. J. Hydrology, 559, 698-710, Crossref.

Barlage, M., M. Tewari, F. Chen, G. Miguez-Macho, Z.L. Yang, and G.-Y. Niu, 2015: The effect of groundwater interaction in North American regional climate simulations with WRF/Noah-MP. Clim. Change, 129, 485-498, Crossref.

Barlow, M., 2011: Influence of hurricane-related activity on North American extreme precipitation. Geophys. Res. Lett., 38, L04705, Crossref.

Brauer, N. S., J. B. Basara, C. R. Homeyer, G. M. McFarquhar, and P. E. Kirstetter, 2020: Quantifying precipitation efficiency and drivers of excessive precipitation in postlandfall Hurricane Harvey. J. Hydrometeor., 21, 433452, Crossref.

Case, J. L., 2016: From drought to flooding in less than a week over South Carolina. Results Phys., 6, 1183-1184, Crossref.

, and B. T. Zavodsky, 2018: Evolution of 2016 drought in the southeastern United States from a land surface modeling perspective. Results Phys., 8, 654-656, Crossref.

, W. L. Crosson, S. V. Kumar, W. M. Lapenta, and C. D. Peters-Lidard, 2008: Impacts of high-resolution land surface initialization on regional sensible weather forecasts from the WRF model. J. Hydrometeor., 9, 1249-1266, Crossref.

, S. V. Kumar, J. Srikishen, and G. J. Jedlovec, 2011: Improving numerical weather predictions of summertime precipitation over the southeastern United States through a high-resolution initialization of the surface state. Wea. Forecasting, 26, 785-807, $\underline{\text { Crossref. }}$ 
Chen, F., and J. Dudhia, 2001: Coupling an advanced land-surface-hydrology model with the Penn StateNCAR MM5 modeling system. Part I: Model implementation and sensitivity. Mon. Wea. Rev., 129, 569-585, Crossref.

Ek, M. B., K. E. Mitchell, Y. Lin, E. Rogers, P. Grunmann, V. Koren, G. Gayno, and J. D. Tarpley, 2003: Implementation of Noah land surface model advances in the National Centers for Environmental Prediction operational mesoscale Eta model. J. Geophys. Res., 108, 8851, Crossref.

Emanuel, K., 2017: Assessing the present and future probability of Hurricane Harvey's rainfall. Proc. Natl. Acad. Sci., 114, 12681-12684, Crossref.

Evans, C., R. S. Schumacher, and T. J. Galarneau Jr., 2011: Sensitivity in the overland reintensification of Tropical Cyclone Erin (2007) to near-surface soil moisture characteristics. Mon. Wea. Rev., 139, 38483870 , Crossref.

Evensen, G., 2003: The ensemble Kalman filter: Theoretical formulation and practical implementation. Ocean Dyn., 53, 343-367, Crossref.

Fang, Z., G. Dolan, A. Sebastian, and P. B. Bedient, 2014: Case study of flood mitigation and hazard management at the Texas Medical Center in the wake of Tropical Storm Allison in 2001. Nat. Haz. Rev., 15 (3), 1-11, Crossref.

Galarneau, T. J., Jr., and X. Zeng, 2020: The Hurricane Harvey (2017) Texas rainstorm: Synoptic analysis and sensitivity to soil moisture. Mon. Wea. Rev., 148, 2479-2502, Crossref.

, L. F. Bosart, and R. S. Schumacher, 2010: Predecessor rain events ahead of tropical cyclones. Mon. Wea. Rev., 138, 3272-3297, Crossref.

Guan, H., B. Cui, and Y. Zhu, 2015: Improvement of statistical postprocessing using GEFS reforecast information. Wea. Forecasting, 30, 841-854, Crossref.

Hall, T. M., and J. P. Kossin, 2019: Hurricane stalling along the North American coast and implications for rainfall. Clim. Atmos. Sci., 2 (17), 1-9, Crossref.

Hendricks, E. A., R. L. Elsberry, C. S. Velden, A. C. Jorgensen, M. S. Jordan, and R. L. Creasey, 2018: Environmental factors and internal processes contributing to the interrupted rapid decay of Hurricane Joaquin (2015). Wea. Forecasting, 33, 1251-1262, Crossref.

Huang, H., J. M. Winter, and E. C. Osterberg, 2018: Mechanisms of abrupt extreme precipitation change over the northeastern United States. J. Geophys. Res. Atmos., 123, 7179-7192, Crossref.

Jedlovec, G., 2013: Transitioning research satellite data to the operational weather community: The SPoRT paradigm. IEEE Geosci. Remote Sens. Mag., 1, 62-66, Crossref.
Keller, J. H., and Coauthors, 2019: The extratropical transition of tropical cyclones. Part II: Interaction with the midlatitude flow, downstream impacts, and implications for predictability. Mon. Wea. Rev., 147, 1077-1106, Crossref.

Kellner, O., D. Niyogi, M. Lei, and A. Kumar, 2012: The role of anomalous soil moisture on the inland reintensification of Tropical Storm Erin (2007). Nat. Hazards, 63, 15731600, Crossref.

Knight, D. B., and R. E. Davis, 2007: Climatology of tropical cyclone rainfall in the southeastern United States. Phys. Geog., 28, 126-147, Crossref.

, and 2009: Contribution of tropical cyclones to extreme rainfall events in the southeastern United States. J. Geophys. Res., 114, D23102, Crossref.

Kumar, S. V., and Coauthors, 2006. Land information System: An interoperable framework for high resolution land surface modeling. Environ. Model. Softw., 21, 14021415, Crossref.

, C. D. Peters-Lidard, J. L. Eastman, and W.-K. Tao, 2007: An integrated high-resolution hydrometeorological modeling testbed using LIS and WRF. Environ. Model. Softw., 23, 169-181, Crossref.

, R. H. Reichle, C. D. Peters-Lidard, R. D. Koster, X. Zhan, W. T. Crow, J. B. Eylander, and P. R. Houser, 2008: A land surface data assimilation framework using the Land Information System: Description and applications. Adv. Water Res., 31, 1419-1432, Crossref. , R. H. Reichle, R. D. Koster, W. T. Crow, and C. D. Peters-Lidard, 2009: Role of subsurface physics in the assimilation of surface soil moisture observations. $J$. Hydrometeor., 10, 1534-1547, Crossref.

Kunkel, K. E., and S. M. Champion, 2019: An assessment of rainfall from Hurricanes Harvey and Florence relative to other extremely wet storms un the United States. Geophys. Res. Lett., 46, 13500-13506, Crossref.

, D. R. Easterling, D. A. Kristovich, B. Gleason, L. Stoecker, and R. Smith, 2012: Meteorological causes of the secular variations in observed extreme precipitation events for the conterminous United States. $J$. Hydrometeor., 13, 1131-1141, Crossref.

Lau, K-M., Y. P. Zhou, and H.-T. Wu, 2008: Have tropical cyclones been feeding more extreme rainfall? $J$. Geophys. Res., 113, D23113, Crossref.

Liu, M., and J. A. Smith, 2016: Extreme rainfall from landfalling tropical cyclones in the eastern United States: Hurricane Irene (2011). J. Hydrometeor., 17, 2883-2904, Crossref.

Liu, Y., C. D. Peters-Lidard, S. Kumar, J. L. Foster, M. Shaw, Y. Tian, and G. M. Fall, 2013: Assimilating satellite-based snow depth and snow cover products for improving snow predictions in Alaska. Adv. Water Res., 54, 208-227, Crossref. 
Marciano, C. G., and G. M. Lackmann, 2017: The South Carolina flood of October 2015: Moisture transport analysis and the role of Hurricane Joaquin. $J$. Hydrometeor., 18, 2973-2990, Crossref.

McDonough, K. R., S. L. Hutchinson, J. M. S. Hutchinson, J. L. Case, and V. Rahmani, 2018: Validation and assessment of SPoRT-LIS surface soil moisture estimates for water resources management applications. $J$. Hydrology, 566, 43-54, Crossref.

Miller, W., and D.-L. Zhang, 2019: Understanding the unusual looping track of Hurricane Joaquin (2015) and its forecast errors. Mon. Wea. Rev., 147, 2231-2259, Crossref.

Nair, U. S., and Coauthors, 2019: Influence of land cover and soil moisture based brown ocean effect on an extreme rainfall event from a Louisiana Gulf Coast tropical system. Sci. Rep., 9, 17136, Crossref.

Niu, G.-Y., and Coauthors, 2011: The community Noah land surface model with multiparameterization options (Noah-MP): 1. Model description and evaluation with local-scale measurements. J. Geophys. Res., 116, D12109, Crossref.

Paerl, H. W., N. S. Hall, A. G. Hounshell, R. A. Luettich Jr., K. L. Rossignol, C. L. Osburn, and J. Bales, 2019: Recent increase in catastrophic tropical cyclone flooding in coastal North Carolina, USA: Long-term observations suggest a regime shift. Sci. Rep., 9, 10620, Crossref.

Peters-Lidard, C. D., and Coauthors, 2007: Highperformance Earth system modeling with NASA/ GSFC's Land Information System. Innovations Syst. Softw. Eng., 3, 157-165, Crossref. , and __ 2015: Integrated modeling of aerosol, cloud, precipitation and land processes at satellite-resolved scales. Environ. Model. Softw., 67, 149-159, Crossref.

Santanello, J. A., Jr., S. V. Kumar, C. D. Peters-Lidard, K. Harrison, and S. Zhou, 2013: Impact of land model calibration on coupled land-atmosphere prediction. $J$. Hydrometeor., 14, 1373-1400, Crossref.

Shepherd, J. M., A. Grundstein, and T. L. Mote, 2007: Quantifying the contribution of tropical cyclones to extreme rainfall along the coastal southeastern United States. Geophys. Res. Lett., 34, L23810, Crossref.

Sturdevant-Rees, P., J. A. Smith, J. Morrison, and M. L. Baeck, 2001: Tropical storms and the flood hydrology of the central Appalachians. Water Resour. Res., 37, 21432168, Crossref.

Svoboda, M., and Coauthors, 2002: The Drought Monitor. Bull Amer. Meteor. Soc., 83, 1181-1190, Crossref.

van Oldenborgh, G. J., and Coauthors, 2017: Attribution of extreme rainfall from Hurricane Harvey, August 2017. Environ. Res. Lett., 12, 124009, Crossref.
Vargas, M., Z. Jiang, J. Ju, and I. A. Csiszar, 2015: Realtime daily rolling weekly green vegetation fraction (GVF) derived from the Visible Imaging Radiometer Suite (VIIRS) sensor onboard the SNPP satellite. Preprints, 20th Conf. on Satellite Meteorology and Oceanography, Phoenix, AZ, Amer. Meteor. Soc., P210. [Available online at ams.confex.com/ ams/95Annual/webprogram/Paper259494.html.]

Villarini, G., R. Goska, J. A. Smith, and G. A. Vecchi, 2014: North Atlantic tropical cyclones and U.S. flooding. Bull. Amer. Meteor. Soc., 95, 1381-1388, Crossref.

Wang, S.-Y. S., L. Zhao, and R. R. Gillies, 2016: Synoptic and quantitative attributions of the extreme precipitation leading to the August 2016 Louisiana flood. Geophys. Res. Lett., 43, 11805-11814, Crossref.

, __ J.-H. Yoon, P. Klotzbach, and R. R. Gillies, 2018: Quantitative attribution of climate effects on Hurricane Harvey's extreme rainfall in Texas. Environ. Res. Lett., 13, 054014, $\underline{\text { Crossref. }}$

Wang, X., D. Parrish, D. Kleist, and J. Whitaker, 2013: GSI 3DVar-based ensemble-variational hybrid data assimilation for NCEP Global Forecast System: Singleresolution experiments. Mon. Wea. Rev., 141, 40984117, Crossref.

Wasko, C., and R. Nathan, 2019: Influence of changes in rainfall and soil moisture on trends in flooding. $J$. Hydrology, 575, 432-441, Crossref.

White, A. T., K. D. White, C. R. Hain, and J. L. Case, 2020: River flood prediction using a Long Short-Term Memory recurrent neural network. Preprints, 19th Conf. on Artificial Intelligence for Environmental Science, Boston, MA, Amer. Meteor. Soc., 11A.3. [Available online at ams.confex.com/ams/2020Annual/meetingapp. cgi/Paper/369151.]

White, K. D., J. L. Case, and B. T. Zavodsky, 2017: The SPoRT Land Information System and the research to operations process. Preprints, 28th Conf. on Weather Analysis and Forecasting/24th Conf. on Numerical Weather Prediction, Seattle, WA, Amer. Meteor. Soc., 7A.5. [Available online at ams.confex.com/ams/97Annual/webprogram/ Paper307825.html.]

Xia, Y., and Coauthors, 2012: Continental-scale water and energy flux analysis and validation for North American Land Data Assimilation System project phase 2 (NLDAS-2): 1. Intercomparison and application of model products. J. Geophys. Res., 117, D03109, Crossref.

Xia Y., M. B. Ek, C. D. Peters-Lidard, D. Mocko, M. Svoboda, J. Sheffield, and E. F. Wood, 2014: Application of USDM statistics in NLDAS-2: Optimal blended NLDAS drought index over the continental United States. J. Geophys. Res. Atmos., 119, 2947-2965, Crossref. 
Zavodsky, B. T., J. L. Case, C. B. Blankenship, W. L. Crosson, K. D. White, 2013: Application of next-generation satellite data to a high-resolution, real-time land surface model. Earthzine, J. Kart, Ed., Institute of Electrical and Electronics Engineers. [Available online at earthzine. org/application-of-next-generation-satellite-data-to-ahigh-resolution-real-time-land-surface-model/.] , and K. D. White, 2016: Development of an objective high spatial resolution soil moisture index. Preprints, 30th Conf. on Hydrology, New Orleans, LA, Amer. Meteor. Soc., P88. [Available online at ams. confex.com/ams/96Annual/webprogram/Paper289068. html.]

Zhang, F., Z. Pu, and C. Wang, 2019: Impacts of soil moisture on the numerical simulation of a post-landfall storm. $J$. Meteor. Res., 33, 206-218, Crossref.

Zhang, J., and Coauthors, 2016: Multi-Radar Multi-Sensor (MRMS) quantitative precipitation estimation: Initial operating capabilities. Bull. Amer. Meteor. Soc., 97, 621-637, Crossref.

Zhang, W., G. Villarini, G. A. Vecchi, and J. A. Smith, 2018: Urbanization exacerbated the rainfall and flooding caused by hurricane Harvey in Houston. Nature, 563, 384-388, Crossref.

Zhou, L., S.-J. Lin, J.-H. Chen, L. M. Harris, X. Chen, and S. L. Rees, 2019: Toward convective-scale prediction within the Next Generation Global Prediction System. Bull. Amer. Meteor. Soc., 100, 1225-1243, Crossref.

Zhou, L., S.-J. Lin, J.-H. Chen, L. M. Harris, X. Chen, and S. L. Rees, 2019: Toward convective-scale prediction within the Next Generation Global Prediction System. Bull. Amer. Meteor. Soc., 100, 1225-1243, Crossref.

Zhou, X., Y. Zhu, D. Hou, Y. Luo, J. Peng, and R. Wobus, 2017: Performance of the new NCEP Global Ensemble Forecast System in a parallel experiment. Wea. Forecasting, 32, 1989-2004, Crossref. 